\title{
Study on Aerosol Optical Depth in Winter and Summer Season in Bhaktapur
}

\author{
Niranjan Prasad Sharma ${ }^{1}$, Bal Krishna Sapkota ${ }^{1}$, Binod Bhattarai ${ }^{1}$, Berit Kjeldstad ${ }^{2}$ \\ ${ }^{1}$ Department of Engineering Science \& Humanities, Pulchowk Campus, Institute of Engineering, TU, Nepal \\ Email: sharmaniranjanprasad@hotmail.com \\ ${ }^{2}$ Department of Physics, Norweigan University of Science and Technology, Trondheim, Norway
}

\begin{abstract}
Aerosol optical depth in winter and summer season, 2009 was studied in Bhaktapur (Kausaltar). Spectral aerosol optical depth (AOD) measurements were estimated from a Microtops II Sun Photometer. The results indicated high values in summer and low values in winter. It also showed that AOD is larger in shorter wavelength and gradually decreases towards longer wavelength. The increasing value of AOD in summer season may be due to the accumulation of high speed dust particles. The lower values in winter months are due to the reduction of bigger particles. The spectral dependence of AOD on January 27 was found to be $0.64,0.52$, 0.48 and 0.35 . The AOD at $340 \mathrm{~nm}$ in January and July were 0.63 and 0.62 , respectively. The maximum and minimum value of AOD at $340 \mathrm{~nm}$ in the month of April and August were recorded as 1.62 and 0.56 , respectively.
\end{abstract}

Keywords: Sun photometer, Aerosol, Aerosol optical depth, Angstrom parameters, Irradiance

\section{Introduction}

Aerosols are tiny particles in solid or liquid phase suspended in the air. Some occur naturally, originating from volcanoes, wind blown dust, forest and grassland fires, living vegetation and sea spray. They occur over a wide range of sizes extending from $10^{-2} \mu \mathrm{m}$ to about $10^{2} \mu \mathrm{m}$. Aerosol particles larger than about $1 \mu \mathrm{m}$ in size are produced by wind blow dust and sea salt from sea spray and bursting bubbles. Aerosols smaller than $1 \mu \mathrm{m}$ are mostly formed by condensation processes such as conversion of sulphur dioxide $\left(\mathrm{so}_{2}\right)$ gas (released from volcanic eruptions) to sulphate particles and by formation of soot and smoke during processes. After formation, the aerosols are mixed and transported by atmospheric motions and are primarily removed by cloud and precipitation processes. Aerosols interact both directly and indirectly with the earth's radiation budget and climate. They scatter and absorb optical radiation depending upon their size distribution, refractive index and total atmospheric loading. This results in attenuation or extinction of solar radiation reaching the earth's surface (Ranjan et al., 2007).

Bhaktapur is a major tourist area of the Kathmandu Valley and the maximum value of aerosol optical depth can cause adverse effects on human health. Continuous monitoring of aerosol was lacking in Bhaktapur but since April, 2008 it is continuing. Daily monitoring of AOD helps to estimate variation over the measurement site. The main objective of this paper is to retrieve diurnal, winter and summer variation of aerosol optical depth. It also presents variation of relative humidity and temperature in January and July. Section 2 represents site selection and 
instrumentation. Section 3 covers results and discussion and conclusions are included in Section 4.

\section{Instrumentation and Site}

Kausaltar (N27\% 40 , E $85^{\circ} 22^{\prime}$ ), a part of Bhaktapur district, lays in the eastern region of Kathmandu at an elevation, of $1314 \mathrm{~m}$. The instrument used to monitor AOD is a MicroTops II Sun Photometer, manufactured by Solar Light Inc, USA. It works on the method of differential optical absorption and scattering. It is a portable multi-band instrument, comprising of five different collimators working in ultraviolet $(340 \mathrm{~nm})$, visible $(440,500,675 \mathrm{~nm})$ and infrared $(870 \mathrm{~nm})$ wavelengths. The bandwidth for channel 340 is $2 \mathrm{~nm}$ and for the rest of the channels it is about $10 \mathrm{~nm}$. The photometer consists of an interference filter, photodiode and necessary electronic devices. The field of view of the input optics is about $2.5^{\circ}$. During measurement, the window of the instrument is directed towards the sun and it measures direct solar irradiance. Data was recorded from sunrise to sunset throughout the day at an interval of about half an hour. Relative Humidity data was collected from the Department of Hydrology and Meteorology, Government of Nepal and was used in the analysis.

\subsection{Angstrom Formula and Coefficients}

The Angstrom exponent is determined from the spectral dependence of the measured optical depth and the coefficient is computed using the following equation:

$$
(\lambda)=\beta \lambda^{-\alpha} \quad \ldots \text { (1) (Angstrom et al., 1961) }
$$

where $\lambda$ is the wavelength and $\beta$ is the aerosol turbidity coefficient

Latah et al. pointed out that large value of a indicates a relatively high ratio of small particles to large particles. When aerosol particle size approaches the size of air molecules, a should approach 4 and for very large particles it should approach 0 . Thus, the larger values of a indicates relatively small size particles and the turbidity coefficient $\beta$ gives an estimate of aerosol loading over the site (Ranjan et al., 2007).

\section{Results and discussion}

May to August is normally the rainy months of the year in Nepal. The weather gets dry with heavy sunshine in March and April. Cloud cover is frequently seen throughout the year and during cloud cover and the rainy season daytime data recording is not significant.

\subsection{Diurnal Variation of AOD}

The spectral dependence of AOD at 340, 440, 500 and $675 \mathrm{~nm}$ in January 27 was found to be $0.64,0.51,0.48$ and 0.36 respectively at 2.89 UT [Hour] as shown in Figure 1. The figure indicates that AOD increases for shorter wavelength and gradually decreases towards longer wavelengths. The AOD at $340 \mathrm{~nm}$ in January 1 and June 1 were found to be 0.92 and 1.24 as shown in Figure 2. The irradiance in January and July 9 were 0.38 and 0.72 respectively as shown in Figure 3. The AOD is higher in the morning than the afternoon in Kausaltar. High AOD is attributed to a highly populated urban environment, cloudy conditions, and Tinkunne Surya Binayak road construction under study. 


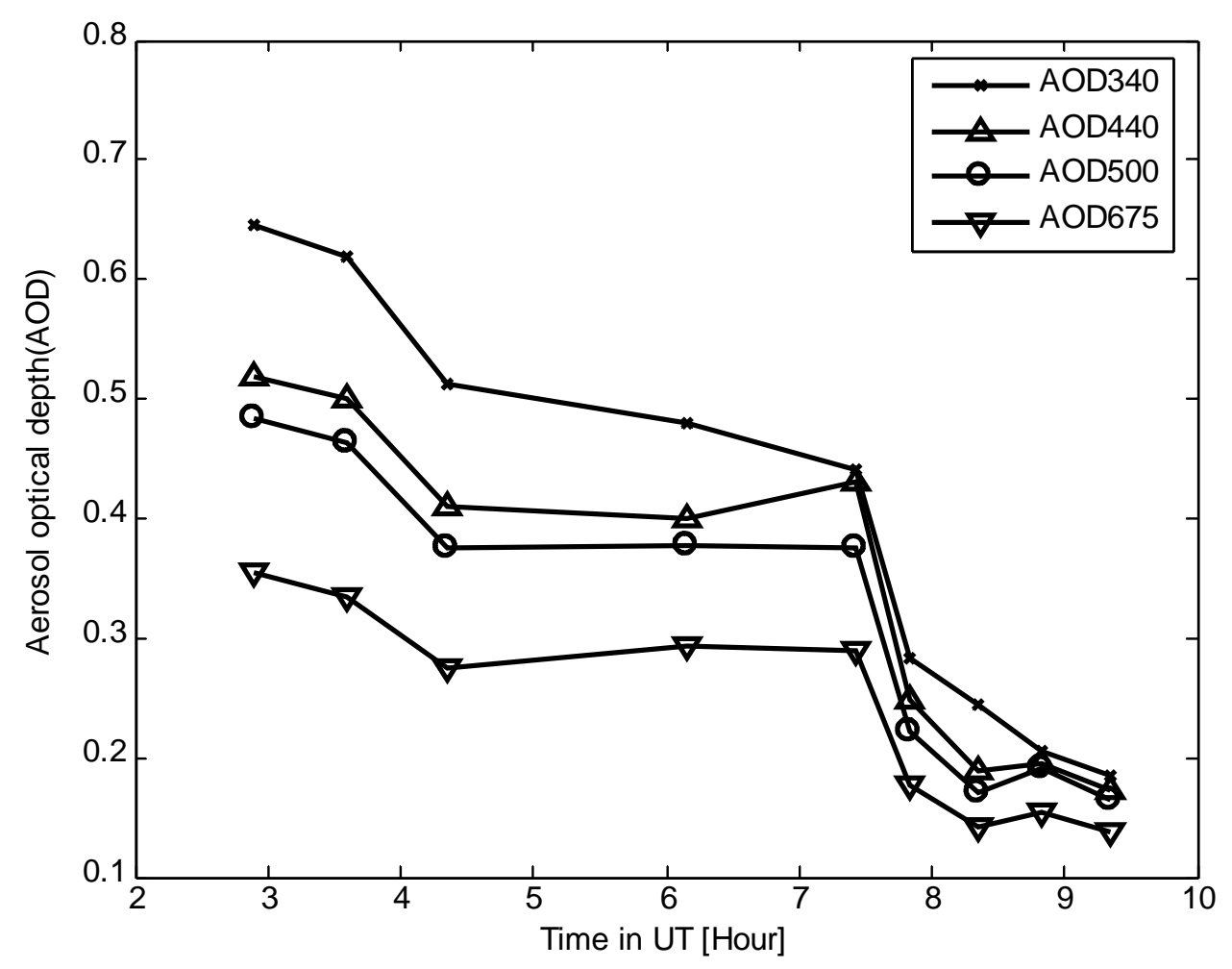

Figure 1: Spectral dependence of Aerosol optical depth on January 27

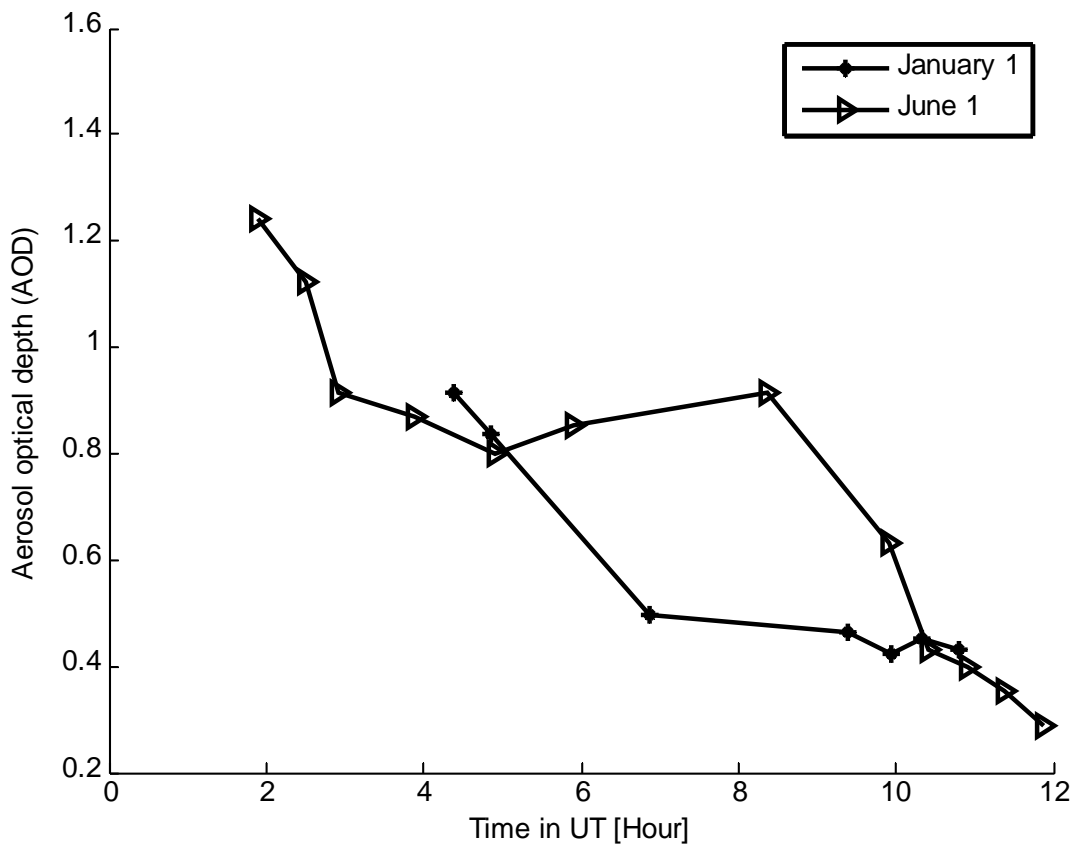

Figure 2: variation of aerosol optical depth on January 1 and June 1, at $340 \mathrm{~nm}$ 


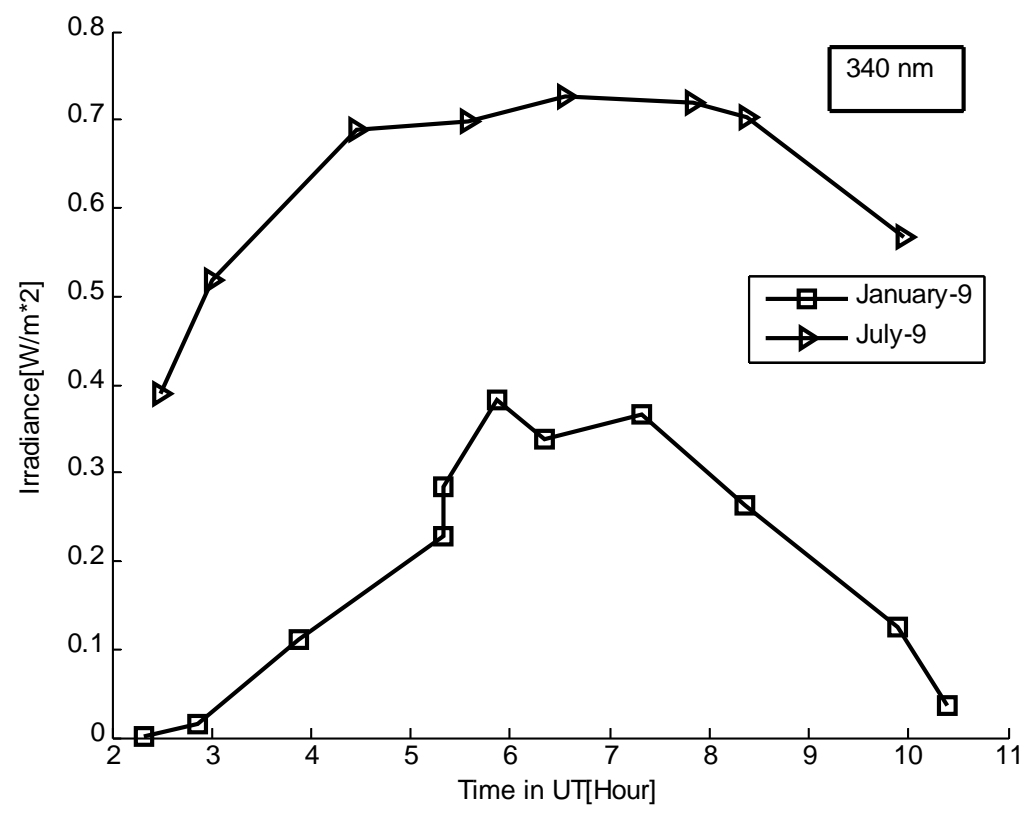

Figure 3: Variation of solar irradiance in January 9 and July 9

\subsection{Variation of Angstrom parameters $\alpha$ and $\beta$}

The Angstrom parameters $\alpha$ and $\beta$ give the instantaneous value of the turbidity of the atmosphere (Cachorro et al., 1987). In spite of the poor correlation between the AOD and $\alpha$ parameter (Holben et al., 1998; Cachorro et al., 2000), values of both quantities must be considered for a realistic analysis. The studies by Cachorro et al., (2001) showed that $\alpha$ value depends strongly on the spectral range. In the present study, Angstrom parameters were studied in the spectral range of $340-675 \mathrm{~nm}$. Table 1 represents the variations of wavelength exponent $(\alpha)$ and Aerosols concentration ( $\beta$ ). Minimum values of $\alpha$ indicate the presence of coarse-mode aerosol particles whereas higher values indicate the reduction of concentration coarse-mode particles in Figure 4. The value of wavelength $\alpha$ and $\beta$ in April 7, at Kausaltar were 0.79 and 0.32, respectively, as shown in Figure 4. It indicates the high accumulation of aerosols particles in Kausaltar.

Table 1: Wavelength exponent $(\alpha)$ and turbidity coefficient $(\beta)$

\begin{tabular}{|l|l|c|c|c|}
\hline Date & Location & $\begin{array}{c}\text { Time in UT } \\
{[\text { Hour }]}\end{array}$ & $\begin{array}{c}\text { Wavelength } \\
\text { exponent }(\alpha)\end{array}$ & $\begin{array}{c}\text { Aerosols concentration } \\
(\beta)\end{array}$ \\
\hline March 7 & Kausaltar & $07: 23: 32$ & 0.47 & 0.83 \\
\hline April 7 & Kausaltar & $06: 54: 55$ & 0.79 & 0.32 \\
\hline June 7 & Kausaltar & $07: 04: 05$ & 0.73 & 0.83 \\
\hline
\end{tabular}




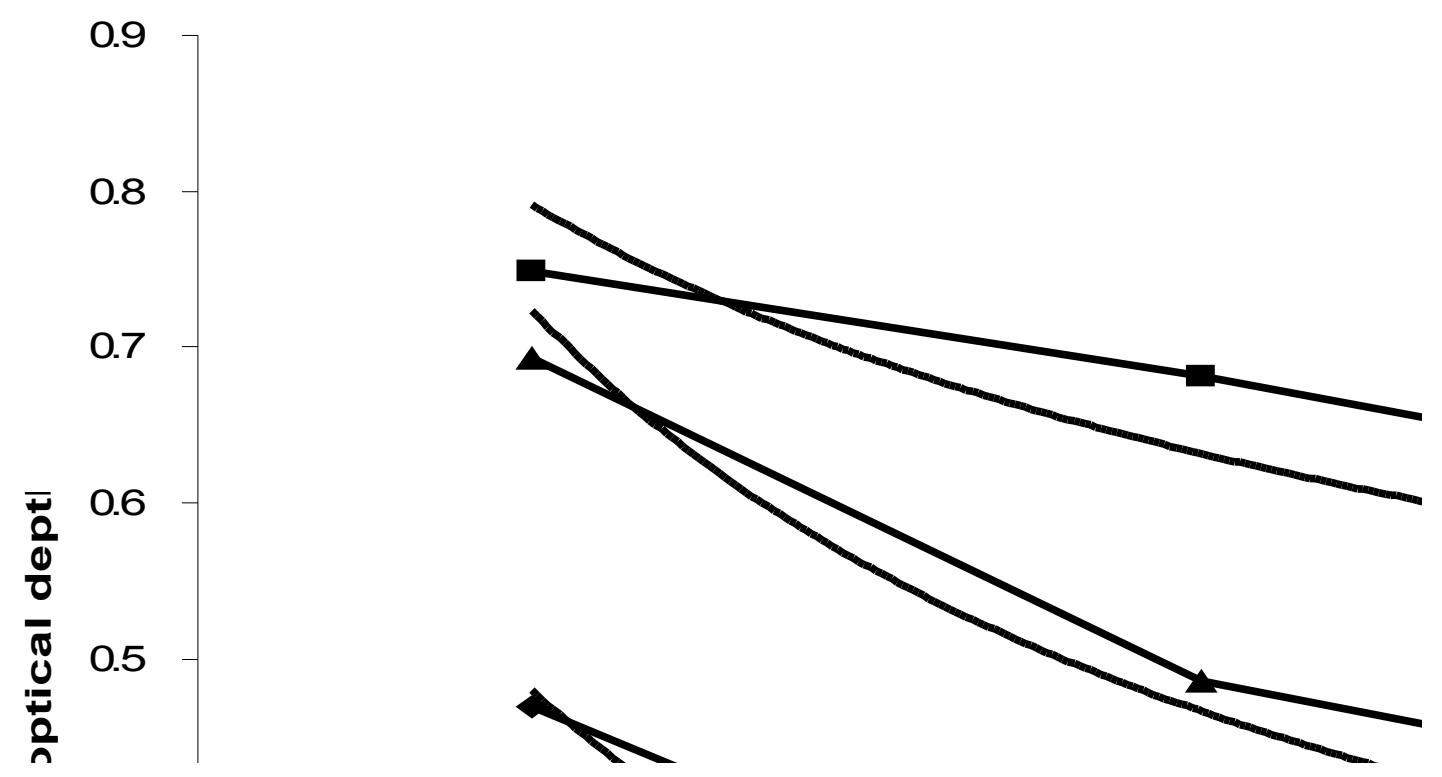

Figure 4: Variation of aerosol optical depth in March, April and June 7

\subsection{Seasonal variation of AOD}

The maximum value of AOD in winter season is 1.03 whereas in summer season the value obtained is 1.46 as shown in Figure 5 and Figure 6. The winter variation of AOD is lower than the summer variation. AOD at all wavelengths are high during summer, prior to the monsoon and after the monsoon rain washes out the pollutants present in the atmosphere.

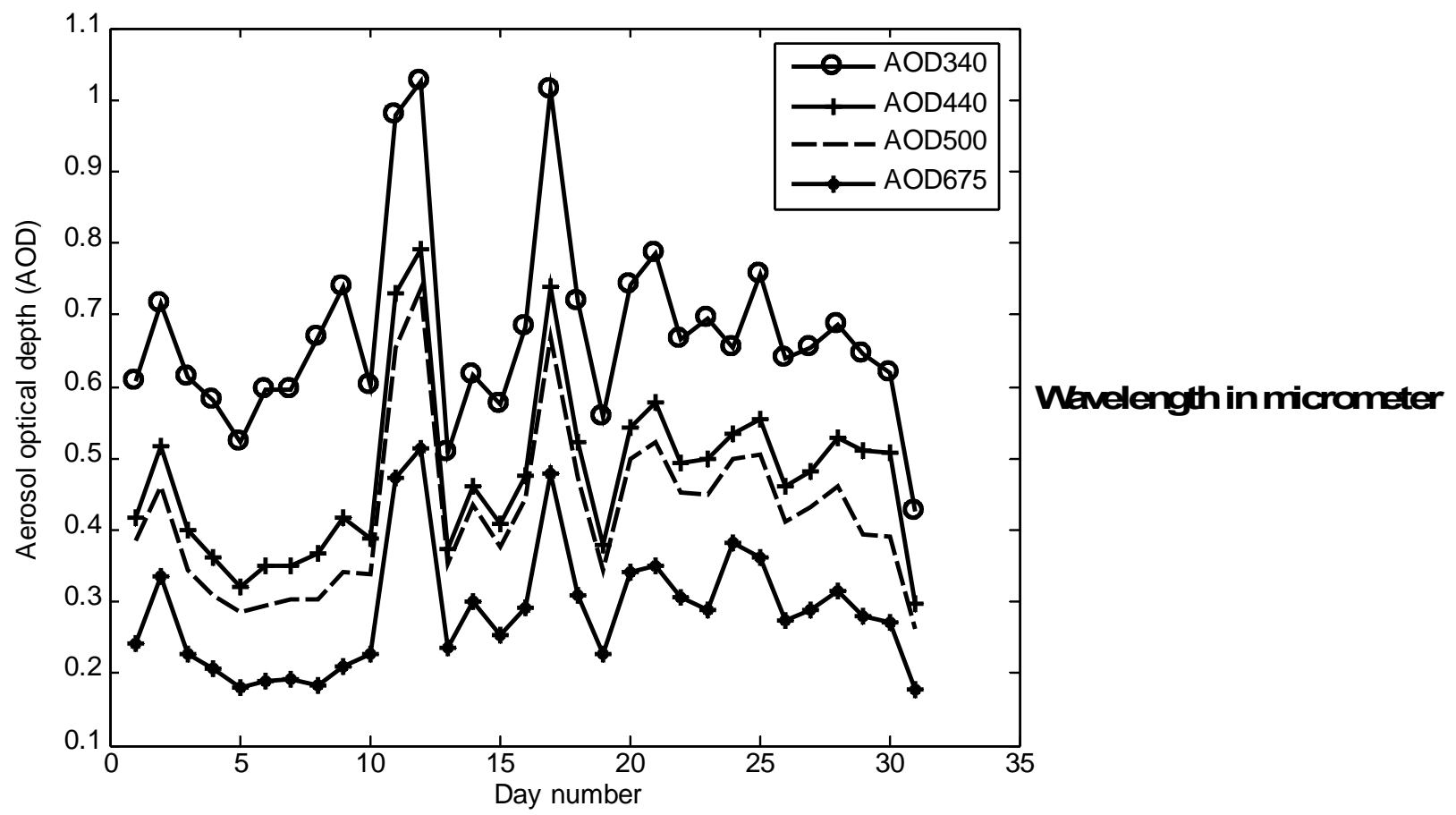

Figure 5: Variation of aerosol optical depth in winter season 


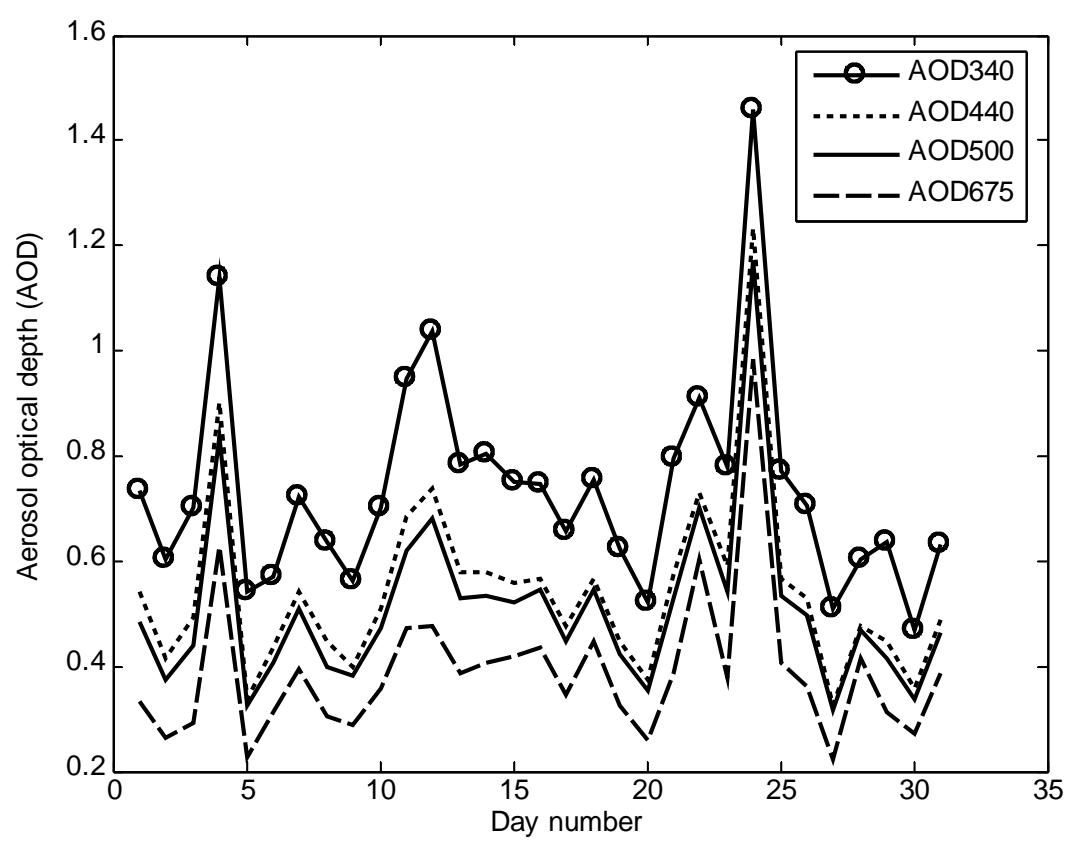

Figure 6: Variation of aerosol optical depth in summer season

\subsection{Meteorological Parameters}

In winter and summer season the meteorological parameters showed significant fluctuations. The relative humidity was normally greater than $97 \%$ in winter and summer season at 5:45 A.M. Relative humidity and ambient air temperature in January and July is shown in Figure7 and Figure 8, respectively. January and February 2009 experienced no rainfall in Kathmandu valley. The maximum and minimum rainfall recorded were $99 \mathrm{~mm}$ and $0.1 \mathrm{~mm}$ in July 27 and March 29, respectively. Relative humidity on January 9 , a clear day, was found to be increased by $1.01 \%$ as compared to January 14 , in turbid day.

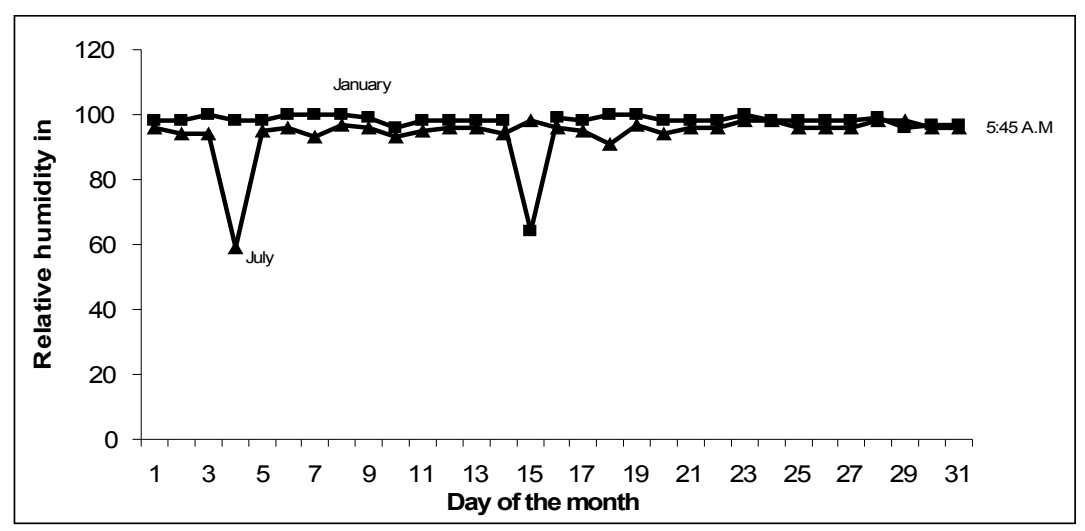

Figure 7: variation of relative humidity in January and July 


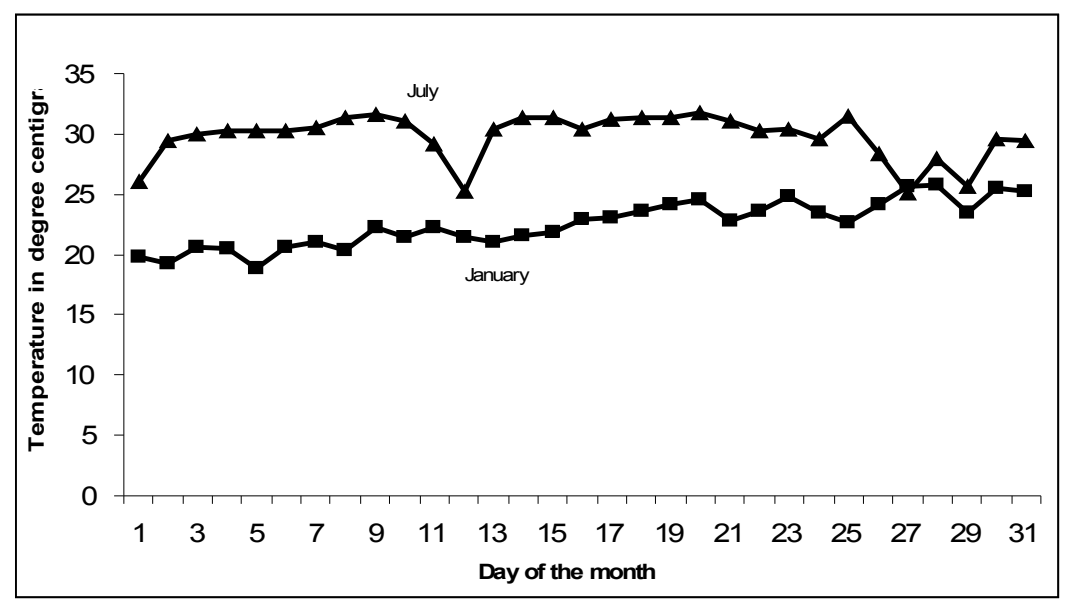

Figure 8: Variation of temperature in January and July

\section{Conclusions}

Aerosols optical depth in Kausaltar showed higher values at shorter wavelengths which gradually decreases towards longer wavelengths for both winter and summer seasons. Higher and lower values of AOD are due to fine and coarse particle loading. Systematic spectral dependence of AOD exhibits a temporal pattern with high AOD values either in the morning $(10: 30 \mathrm{hrs})$ or afternoon $(13: 00 \mathrm{hrs})$ local time. It is mainly due to local activities, rush hour traffic, cloudy conditions and Tinkunne Surya Binayak road construction. In March, the maximum AOD was recorded to be 0.67 . The relative humidity almost remained steady in January and July except on January 15 and July 4 . The steady value of relative humidity is due to the stability of local meteorological conditions.

\section{Acknowledgements}

The author wishes to thank Solar Radiation and Aerosol Project in the Himalaya region (SAHR), Pulchowk Campus for providing data and other support.

\section{REFERENCES}

[1] Angstrom, A.K. (1961). Techniques of Determining the Turbidity of the Atmosphere. Tellus XIII:214

[2] Cachorro, V.E., Vergaz R and de Frutos A.M. (2001). A Quantitative comparison of $\alpha$ Angstrom Turbidity Parameter Retrieved in Different Spectral Ranges Based on Spectro-radiometer Solar Radiation Measurements, Atmos. Environ. 35: 5117-5124

[3] Cachorro,V.E., Casanova,J.L and Frutos, A.M. (1987). The influence of Angstrom Parameters on Calculated direct solar Spectral Irradiance at High Turbidity.Sol.Ener.39: 399-407 
[4] Cachorro,V.E., Duran,P., Vergaz, R. and de Frutos, A.M. (2000). Columnar Physical and Radiative Properties of Atmospheric Aerosol in North Central Spain. J. Geophys. Res. 105: 7161-7175

[5] Holben, B.N., Eck.T.F., Slutsker,I., Tanre,D., Buis,J.P., setzer,A., Vermote,E., Reagan, J.A., Kaufman.Y.J., Nakajima,T., Lavenu. F., Jankowiak, I. and Smirnov,A.(1998). AERONET-A Federated Instrument Network and data Archive for aerosol Characterization. Rem. Sens. Environ. 66: 1-16

[6] Holben, B.N., Tanre, D., Smirnov, A., Eck, T.F., Slutsker, I., Abuhassan, N., Newcomb W.W., Schafer, J.S., Chatenet, B., Lavenu, F., Kaufman, Y.J., Castle, J.V., Setzer, A., Markham, B., Clark, D., Frouin, R., Halthore, R., Karneti, A., O'Neil, N.T., Pietras, C., Pinker, R.T., Voss, K. and Zibordi, G. (2001). An Emerging Ground-based Aerosol Climatology: Aerosol Optical Depth from Aeronet.J.Geophys Res. 106: 12067-12097

[7] http://www.dhm.gov.np

[8] Jianjun.La, Youfei.Z ${ }^{\mathrm{a}, *}$, Zhanqing. ${ }^{\mathrm{b}}$, Rongjun. $\mathrm{W}^{\mathrm{a}}$ (2008). Ground- based remote sensing of aerosol optical properties in one city in Northwest china, atmospheric research 89 (2008) 194-205

[9] Latha K M \& Badrinath K V S, Association of aerosol optical depth with near surface aerosol properties in urban environment, Indian J Radio \& Space Phys,33 (2004) 256

[10] Ranjan, R. R., Ganguly D.N; Joshi; H.p and Iyer, K.N; (2007). Study of aerosol optical depth and precipitable water vapor content at Rajkot, a tropical semi - arid station. Indian J. Radio and space phys.pp. 27.32

[11] Ranjan, R.R., Joshi, H.P. and Iyer, K.N. (2007). Spectral Variation of Total Column Aerosol Optical Depth over Rajkot: A Tropical Semi-Arid Indian Station. Aerosol Air Qual. Res. 7:33-45 